Archivum, LXIX, 2019, pp. 43-83

\title{
Lázaro lee El Lazarillo: algunas reflexiones atunescas sobre la recepción inmediata del texto
}

\author{
José Antonio Calzón García \\ Universidad de CANTABria
}

Recibido: 10/10/2018

Aceptado: 10/05/2019

\begin{abstract}
RESUMEN:
El artículo analiza La Segunda Parte de Lazarillo de Tormes a partir de su relación con la obra original de 1554, considerando el tex to como el primer testimonio fidedigno y detallado de la recepción inmediata que tuvo la obra primigenia. En este sentido, se valora la naturaleza subversiva de ambos textos, desde el punto de vista del realismo y la verosimilitud, al tiempo que se estudia cómo el autor de la continuación analizó, reprodujo y/o reformuló diversos elementos estructurales presentes en el Lazarillo original.
\end{abstract}

PALABRAS CLAVE: Lazarillo, recepción, picaresca, fantasía, continuación, narratario.

Lázaro reads Lazarillo: some tuna reflections about the immediate reception of the text

\footnotetext{
ABSTRACT:

The article analyses the Second Part of Lazarillo de Tormes from its connection with the original work, published in 1554, by considering the text as the first reliable
} 
and detailed testimony of how the original novel was immediately received. In this sense, the subversive nature of both texts is examined, regarding realism and plausibility. At the same time, it is studied how the author of the continuation analized, copied and/or reformulated several structural elements used in the original Lazarillo.

KEYWORDS: Lazarillo, reception, picaresque, fantasy, continuation, narratee.

\section{Introducción}

La Segunda Parte de Lazarillo de Tormes, publicada en Amberes de forma anónima en 1555, ha sufrido asimétricos vaivenes con el correr de la historia, siendo por lo general, en palabras de Núñez Rivera (2003: 369), peor tratada que la secuela de Juan de Luna. Así, mientras que, tal y como apunta Piñero Ramírez (2014), la obra - a pesar de ser inscrita por el inquisidor Fernando de Valdés en su Cathalogus librorum (1559) - fue editada varias veces a lo largo de la segunda mitad del siglo XVI ${ }^{1}$, y traducida pocos años después al inglés, francés e italiano - señal inequívoca de su éxito inicial-, siglos más tarde la novela se vería "arrumbada en ediciones escasas y poco fiables" (Piñero, 1988: 7)², soportando los escasos estudios de filólogos ${ }^{3}$ que por lo general optarían por fustigarla sin piedad, como tan paradigmáticamente evidencian los juicios de Marcelino Menéndez Pelayo al respecto de la obra (Núñez Rivera, 2003: 337): "es de todo punto necia e impertinente, y el anónimo continuador dio muestras de no entender el original que imitaba. Convirtióle en una alegoría insulsa, cuya acción pasa en el reino de los atunes" (Menéndez Pelayo, 1978: 143). En resumidas cuentas, fruto en gran medida de su elemento nuclear, esto es, la metamorfosis del protagonista en atún (Piñe-

1 No obstante, Hasson (2014: 95) apunta cómo ya en el siglo XVI se consideró a la Segunda Parte "como un texto bastardo, disparatado e indigno de ser leído".

2 El propio Piñero (1988: 14) apunta a este respecto el significativo hecho de que la obra no se imprimiese en España hasta mediados del siglo XIX.

3 Sobre esto, indicará Rodríguez López-Vázquez (2014: 13-14) que “el texto mismo, desatendido en su tratamiento filológico, se ha transmitido con evidente deterioro tanto en su fijación como en la atribución de su autoría". 
ro, 1988: 37), "la Segunda Parte no tuvo mucho éxito ni de público ni de crítica. Siempre se presentó al amparo de su original. Resultaba, a todas luces, una obra extraña, que chocaba con el Lazarillo primero del que pasaba por continuación" (Piñero, 1988: 17). De igual modo, Hasson (2014: 96) insiste en señalar cómo una parte importante de la crítica actual ha seguido la estela, "ocupándose en fútiles comparaciones que terminaron afirmando la inferioridad de la secuela antuerpiense respecto al texto que pretende continuar". Por tanto, obvio es que la continuación anónima publicada en Amberes, a pesar de disfrutar de cierto éxito de público inicial, parece hacer contado con los acerbos pareceres de una crítica respecto a la cual siempre ha sido vista en obligada comparación con la obra de 1554.

\section{Historia de una deuda}

Al margen de quienes han fantaseado con la posibilidad de que los autores de las dos obras anónimas - la seminal de 1554 y su continuación antuerpiense - fuesen la misma perso$\mathrm{na}^{4}$, quien habría "decidido continuar la crítica moral y política

4 Si bien este artículo parte, como hipótesis de trabajo, de un acuerdo de mínimos, el cual presume una lectura atenta llevada a cabo por el autor de la continuación respecto al Lazarillo original, no podemos sustraernos, por sus enormes implicaciones en este y en futuros artículos, a los trabajos recientemente publicados por Rodríguez López-Vázquez (2016, 2017, 2018a, 2018b, 2018c, 2018d y 2018e), y que a su vez están basados en el artículo de Rosa y Suárez (2016). Así, el estudio de estos últimos parte del análisis cuantitativo de la frecuencia de uso de los 150, 1500 y 2500 vocablos más usados en diversos textos del siglo XVI, aplicando una metodología de clusters que opera con un planteamiento cuantitativo y estadístico y que lleva a ordenar la selección en función de su mayor o menor proximidad para con la primera parte del Lazarillo. Los resultados permiten extraer que la segunda parte de 1555 estaría, junto con las obras de Juan Arce de Otálora y Alfonso de Valdés, entre los textos con más coincidencias: "Among the ones more closely related to the autor of the Lazarillo [...] we find Juan Arce de Otálora and Alfonso de Valdés [...] The second part of the adventure of Lázaro de Tormes is also placed together with the first two [...] the first and second part of the Lazarillo cluster pretty closely together" (Rosa y Suárez, 2016: 400-402). A partir de aquí, Rodríguez López-Vázquez (2018c) desarrolla un minucioso estudio estilométrico de carácter cuantitativo, a partir de parámetros léxicos — basados en la localización de índices 
usando la vía alegórica y el entramado de la novela de transformaciones" (Podadera Solórzano, 2014: 177), lo cierto es que no son pocas las concomitancias que entre ambos textos se han encontrado. Así, las "cosas tan señaladas" y "por ventura nunca oídas ni vistas" (p. 3) $)^{5}$ del prólogo de la obra de 1554 parecían una invitación en toda regla a continuar el texto por la vía de la excepcionalidad (Piñero, 2014), al igual que el cierre de la edición de Alcalá, donde claramente se ve la intención de dejar un más que sugerente to be continued a modo de final: "De lo

inclusivos y excluyentes - de las dos partes del Lazarillo, concluyendo que ambos textos "corresponden con una alta probabilidad a un mismo autor [...] el texto más cercano a la primera parte del Lazarillo es el de la segunda parte, lo que apunta a la hipótesis unitaria y permite indagar esa autoría a partir de un repertorio muy amplio" (Rodríguez López-Vázquez, 2018c: 55 y 89). De este modo, Rodríguez LópezVázquez acabará por concluir que "los estudios y análisis basados en verificaciones objetivas apuntan a que ambas partes de la pieza maestra de la literatura española son obra de un mismo autor [y] que ese autor es el príncipe de los heterodoxos españoles, Francisco de Enzinas" (Rodríguez López-Vázquez, 2016: 61). Sin llegar a este punto, y fruto de las concomitancias estilísticas y léxicas entre ambos textos, en este artículo asumimos más bien el enfoque conservador de otras afirmaciones de Rodríguez López-Vázquez (2018e: 150), y que llevan a plantear al menos, de forma incuestionable, que el continuador del texto tenía un conocimiento muy profundo de la obra de 1554: "considerar que el autor de la segunda parte es alguien que no ha comprendido [...] la primera parte del Lazarillo [...] supone, entre otras cosas, que el supuesto continuador, ajeno a la obra original, habría llevado a cabo un minucioso análisis de todos los niveles estilísticos, léxicos y sintácticos del original". De este modo, la conclusión más prudente, a partir de los estudios estilométricos realizados, sería que "hay que asumir como una hipótesis probable que la continuación haya sido escrita por el mismo autor o por uno muy afín estilísticamente" (Rodríguez López-Vázquez, 2018d: 49). De cualquiera de las maneras, asumimos, con Rodríguez López-Vázquez (2018d: 45), la sorpresa que causa pensar que "el continuador no había entendido el concepto e intención picaresca del original": "la crítica académica ha venido estudiando la continuación del Lazarillo como una obra ajena al autor del original en función de cuestiones ideológicas o de prejuicios estéticos que no han sido verificados por métodos objetivos" (Rodríguez López-Vázquez, 2018d: 45).

5 Todas las citas del libro se harán por la edición de Francisco Rico (2011). De igual modo, para evitar la farragosidad, ante el elevado número de citas se mencionará tan solo la página correspondiente, tanto en el texto de 1554 como en su continuación de 1555, para la cual se ha seguido la edición de Pedro M. Piñero (1988). 
que de aquí adelante me suscediere, avisaré a Vuestra Merced" (p. 296) ${ }^{6}$. Por otra parte, el anonimato, no poco frecuente entre muchas de las novelas novedosas que aparecen en el siglo XVI, como El Crotalón o el Viaje de Turquía (Piñero, 1988: 32), permitirá en ambos textos unificar las instancias enunciadoras de autor y narrador.

Junto con el guante recogido con el cierre de la edición de Alcalá $^{7}$ y al margen de elementos puramente estructurales - como el fingido autobiografismo - o más o menos circunstanciales las referencias al vino, al ciego, al arcipreste o a la propia mujer de Lázaro (Piñero, 1988: 33-37) -, la Segunda Parte retomaría igualmente el elemento jocoso de la obra de referencia (Gargano, 2006: 125), al tiempo que intentaría, según Piñero (2014), desarrollar todo aquello que en la obra primigenia habría quedado más o menos oculto. No olvidemos que la continuación antuerpiense comienza con el celebérrimo "en este tiempo estaba en mi prosperidad y en la cumbre de toda buena fortuna" (p. 125), reproducción literal del final de la obra de $1554^{8}$. El guiño, pues, es demasiado obvio como para pensar que el vínculo entre los dos textos se reduce al título, al recurso del autobiografismo y a la superficial caracterización de los protagonistas. A partir de aquí, sin embargo, las dudas se multiplican, en particular por la perplejidad que produce una metamorfosis en apariencia tan

6 No obstante, la crítica no se atreve a dar por zanjada la cuestión, aparentemente perogrullesca, del posible conocimiento, por parte del continuador, de la edición de Alcalá (Piñero, 1988: 12).

7 No deja de llamar la atención que algunos críticos, como Alatorre (2002: 449450), hayan destacado la importancia de la edición de Alcalá, con sus interpolaciones, a la hora de destruir cualquier tipo de ejemplaridad en torno al protagonista, llegando al punto de afirmar que el primer pícaro de la historia sería el Lázaro de la edición alcalaína.

8 No en vano, como señala Rodríguez López-Vázquez (2014: 22-23), “el primer capítulo de la Segunda parte está tan apegado al Lazarillo original que la costumbre editorial, desde la temprana traducción francesa de 1560, ha venido asumiendo su edición conjunta como capítulo final de la primera parte". 
alejada del tono del texto original. ¿Por qué un atún? ¿Acaso, como afirma Núñez Rivera (2003: 348), ha de entenderse en clave metafórica, en cuanto trasunto de la figura del pícaro? ¿Cómo es posible conjugar los más que obvios, e intencionados, vínculos entre la obra original y su continuación antuerpiense con el descaro que supone darle la vuelta a una narración tan paradigmáticamente realista como el Lazarillo con la carnavalesca historia de un joven metamorfoseado en atún?

\section{Lázaro frente a Lázaro, o la escritura de la recepción}

\subsection{El debate en torno al realismo}

\subsubsection{Fantasía versus realismo}

Tal y como hemos apuntado, uno de los principales problemas que plantea La Segunda Parte de Lazarillo de Tormes es el concerniente a la aparente ruptura del realismo presente en el modelo de 1554. La cuestión pasa, pues, por dilucidar si la delimitación entre realidad y fantasía se basa más en la intuición que en la caracterización semántica o si, en efecto, el Lazarillo y su continuación antuerpiense ofrecen dos universos irreconciliables en lo que a su concepto de la representación respecta.

En primer lugar, como ha señalado Torres Rabassa (2015: 189 y 196), "lo fantástico supone empíricamente la noción de realidad", siendo "la cultura [...] lo que determina nuestra simbolización de lo real". En efecto, cada época marca las coordenadas de lo que puede o no suceder (Todorov, 1982: 45), con lo que es el acto de lectura, como tal, el que conforma la experiencia de lo fantástico (Juliana Bazán, 2014: 56; Campra, 2008: 195), ante una situación de vacilación fruto de un hecho que se presenta como real e imaginario al mismo tiempo (Reis Pereira, 2013: 6): "lo fantástico implica pues una integración del lector con el mundo de los personajes: se define por la percepción ambigua que el propio lector tiene de los acontecimientos relatados" (Todorov, 1982: 41). 
En segundo lugar, lo fantástico, entendido de forma laxa, entronca con la noción de transgresión, en este caso de índole semántico-pragmática ${ }^{9}$-al subvertir, mediante un acontecimiento inexplicable, los esquemas comunes de la vida ordinaria (Herrero Cecilia, 2016: 17), horadando "la idea tradicional de verdad" (Torres Rabassa, 2015: 190) -, o, como afirma Juliana Bazán (2014: 54), fruto de una actitud de desafío frente al orden establecido, donde se revela lo reprimido por la cultura dominante (Videira Álvarez, 2015: 157). En este sentido, el surgimiento y desarrollo del género fantástico como tal -claro está que totalmente desvinculado de la picaresca - parece haber alcanzado su punto culminante "en un momento histórico racionalista que admite la ausencia de religión sin que por ello pueda olvidar la herencia de lo sagrado" (González Salvador, 1984: 215), mostrándose, así, en cuanto alternativa pagana a la sacralización de corte religioso. No en vano, en el universo fantástico asistimos a una suerte de milagro, según el cual "algo que no puede ocurrir, sin embargo, ocurre" (Lomeña Cantos, 2013: 379): lo real "se desmorona ante la aparición de lo no racional" (Torres Rabassa, 2015: 192), logrando, sin embargo, que uno y otro, lo racional y lo sobrenatural, convivan "sin rozar con el absurdo" (Juliana Bazán, 2014: 55).

De este modo, la literatura fantástica, alejada del cliché de fantasmas y monstruos, abre un universo que obliga a replantearse la noción de realismo, o al menos a reconsiderar ambos conceptos desde una visión mucho más difusa. Así, Martínez Bonati (2005: 193) llegará a afirmar que el discurso literario "es no solo ficticio sino también tendencialmente fantástico" por la propia naturaleza del acto narrativo. En efecto, al diferenciar entre mundo narrado y discurso narrativo, Bonati se pregunta, por ejemplo, si un modo de narrar verosímil habría de corresponder-

9 "La transgresión fantástica se configura textualmente a partir de lo que he llamado prototipo y que, en su nivel más básico, se reduce a la combinación de dos recursos: un lenguaje mimético (fondo) y un elemento (figura) que rompe la coherencia epistemológica de lo narrado" (Rodríguez Hernández, 2009-2010). 
se con la forma ordinaria de narrar. En otras palabras, "una cosa es la credibilidad de lo dicho; otra, la credibilidad de un acto de decir como acontecimiento posible" (Martínez Bonati, 2005: 195). Todo ello, pues, parece llevarnos a la conclusión de que el discurso literario puede ser verosímil, pero nunca creíble, en la medida en que, "según las reglas del juego, es una fantasía gnoseológica" (Martínez Bonati, 2005: 199).

En resumidas cuentas, la noción de fantasía se enfrenta a un relativismo cultural reforzado por una percepción supeditada en exclusiva a la interpretación del propio lector, ante el cual el universo fantástico - pero también otros - se muestra como un tipo de discurso rebelde, rupturista, que sin embargo está construido sobre los mismos pilares semánticos que cualquier otra modalidad enunciativa que podamos encontrar en el discurso literario. Es decir, no parece haber una base semántico-pragmática lo suficientemente sólida como para afirmar que la narración fantástica y la realista ofrezcan caracterizaciones fenomenológicamente opuestas desde el punto de vista enunciativo, lo que nos lleva de nuevo a la pregunta de si el Lazarillo original y su continuación atunesca desarrollan propuestas literarias antagónicas, complementarias o, incluso, uniformes.

\subsubsection{La fantasía de la continuación antuerpiense}

Recordemos brevemente que el episodio crucial de La Segunda Parte de Lazarillo de Tormes surge de un viaje del pícaro en barco en el cual, ante la inminencia del naufragio, el protagonista se dejará seducir por el poder narcotizante del vino, lo cual acarreará no solo que Lázaro no perezca, ahogado, sino que su cuerpo, una vez sumergido en las aguas, acabe metamorfoseado en atún. A partir de tan peregrino episodio, la obra configura una estructura en la que, como apunta Piñero (1988: 66), el molde picaresco original configura el marco narrativo general de los dos primeros y los dos últimos capítulos, mientras el centro de la historia, esto es, la conversión de Lázaro, sus andanzas marinas y la posterior rehumanización, se articula a partir de los cauces literarios 
de la novela, del roman, al modo de los libros de caballerías. De este modo, la leyenda folklórica del monstruoso hombre-pez (Piñero, 1988: 44) aflora en la obra con la misma libertad con la que, un año antes, el paradigma literario inaudito de la falsa autobiografía de un niño de ímproba familia arrasaba los patrones narrativos de la España del XVI. En efecto, la figura del monstruo, más que ser concebida como una criatura perteneciente a otro mundo, "es el signo de una ausencia de referente o de categoría donde pueda incluírsele" (González Salvador, 1984: 220), al igual que había sucedido un año antes con ese mozo de muchos amos que se colaba, con descaro, entre el universo de caballeros y pastores enamorados. Ahora bien, la dificultad para habitar espacios inexplorados tan ardua pudo ser para el pícaro original - sumergido en las aguas bizantinas, pastoriles y caballerescas de la narrativa idealizante - como para el sosias atunesco que optó por resquebrajar, en apariencia, el paradigma realista que su alter ego había cimentado un año antes.

No obstante, si del Lazarillo original se ha señalado, una y otra vez, su valor como modelo fundacional de la novela realista española, realizando una acerba crítica de grupos sociales como el clero, la baja nobleza o los buscavidas, a buena parte de la crítica tampoco se le escapa que, en lo que a la continuación antuerpiense respecta, "las aventuras de Lázaro en el reino de los atunes deben interpretarse como una alegoría de la sociedad [...] pese a la irrealidad de una situación tan fantástica [...] en ningún momento el autor deja de conectar la obra con la realidad que le rodea" (Mascarell, 2011: 276). En efecto, si, al igual que Ragala (1999: 272), consideramos que "el autor realista no debe transformar o calificar lo observado, sino presentarlo al lector tal como lo ve", cabe plantear La Segunda Parte de Lazarillo de Tormes como un texto donde la fantasía sirve como mecanismo deformador, o carnavalesco, del que echar mano para realizar un análisis social en el que, a ojos del autor, la España del XVI ${ }^{10}$ bien

10 En este sentido, recordemos que el texto ha generado, por parte de la crítica contemporánea, no pocas interpretaciones en clave simbólica, especialmente en el 
cabía, a la hora de ser explicada, dentro de los moldes de la sátira lucianesca, ofreciendo así un relato tan descarnado y cercano al universo conocido por el lector del Quinientos como la fotografía realizada por el autor del Lazarillo de 1554.

\subsubsection{Juegos fantasiosos en el Lazarillo original}

Obvia es, a estas alturas de la labor crítica, la asunción de que el Lazarillo es, por encima de todo, una obra realista, en el sentido de que pretende pasar por real ${ }^{11} \mathrm{y}$ de que es "verosímil o verificable" (Mascarell, 2011: 275). Ahora bien, el hecho de que no se tratase de una historia verdadera, como tal, suponía un nuevo escenario literario, el de la novela realista, ante el cual, sin embargo, el Lazarillo lidiaba con episodios que amenazaban con resquebrajar la pátina de realidad que la obra pretendía transmitir ${ }^{12}$. De igual modo, como apunta Gargano (2006: 127), de ninguna de las

episodio correspondiente a la metamorfosis del protagonista y a su vida en el mar rodeado de atunes. Así, y en función del crítico, podemos ver la obra y su episodio atunesco como un análisis alegórico y descarnado de la sociedad (Mascarell, 2011: 276), una crítica a Carlos V (Zwez, 1970: 48; Navarro Durán, 2010: 4 y 8-9), una metáfora de las conversiones (Hasson, 2014: 95), un texto en clave (Hasson, 2014: 96), una parodia de los relatos caballerescos (Piñero, 2014), una metáfora de los turcos (Núñez Rivera, 2003: 348) o una crítica de las corruptelas en la Corte y en la soldadesca españolas (Piñero, 1988: 27), por citar tan solo algunas de las muchas lecturas más o menos alegóricas que se han hecho de la novela y de su pasaje más célebre.

11 Algo parecido señalará Rico (1987: 46*): “en primera instancia, el Lazarillo es realista porque pretende pasar por real: porque se nos ofrece como de veras escrito por un pregonero vecino de Toledo".

12 Véanse, como ejemplos, el controvertido asunto de si a Lázaro podían o no caberle doce o quince maravedíes en la boca - "pareciome lo más seguro metella de noche en la boca. Porque ya, desde que viví con el ciego, la tenía tan hecha bolsa que me acaeció tener en ella doce o quince maravedís, todo en medias blancas, sin que me estorbase el comer" (p. 40) -, tal y como señala Rico (1987: 79*), el episodio del jarro de vino perforado del tratado I, la deducción del clérigo de que una culebra saqueaba las ratoneras en el tratado II o la inocencia del protagonista ante el episodio de la "casa lóbrega" del tratado III (Martínez Mata, 1984: 106-109), por citar tan solo algunos casos. De igual modo, no pocos críticos han insistido en que nada en la narración permite acreditar que, en rigor, Lázaro tuviera la capacidad de contestar por escrito a "Vuestra Merced" (Cavillac, 2010). 
maneras el Lazarillo prefigura la novela clásica de la edad realista, ya que "resulta todavía fuertemente deudor de la teoría clásica de los niveles, y, en consecuencia, castiga y rescata el defecto de dignidad del protagonista [...] con una toma de distancia cómica". Otros, como Martín Baños (2007: 18), prefieren utilizar el adjetivo realista de acuerdo con las coordenadas del siglo XVI, evitando así caer en el anacronismo ${ }^{13}$. En este sentido, también Ragala (1999: 273) insiste en que en los pasajes del Lazarillo en los que el autor anónimo "trata de proporcionar rasgos que se relacionan estrechamente con la época que representa, lo hace de un modo tan satírico y deformado que el lector no alcanza a averiguar la veracidad o no de lo contado y tan solo se fija en la farsa que lo acompaña". De este modo, el realismo en la obra pasaría más bien por ofrecer un conjunto de "técnicas literarias" o "modo de representación"14 (Ragala, 1999: 273) que el intencionado esfuerzo por construir un material verdaderamente documental, amén de la frecuente presencia de elementos extraídos del folklore (Martínez Mata, 1984: 106), como la pareja del ciego y su lazarillo (Ragala, 1999: 276). Y así, urdiendo esta "mentira realista" puramente literaria (Ragala, 1999: 284), el autor de la obra de 1554 habría desarrollado un relato donde "no podemos utilizar el concepto de realismo [...] de una forma simplista (al estilo decimonónico), como mera copia de la realidad" (Martínez Mata, 1984: 109). Por el contrario, quien haya sido el responsable del Lazarillo habría llevado a cabo un ejercicio de exploración semántico-referencial en el que probablemente tuviera más claro lo que no quería hacer - baste recordar al respecto las novelas bizantinas, pastoriles o caballerescas - que lo que verdaderamente pretendía.

13 “Uno de los principios básicos de la narración renacentista era la verosimilitud, que requería, de un lado, una correspondencia 'realista' o 'veraz' entre la ficción y el mundo verdadero, y, de otro lado, lo que hoy denominaríamos 'lógica interna del relato'"' (Martín Baños, 2007: 19).

14 "El realismo del Lazarillo no depende de la procedencia de los personajes y episodios narrados, sino de la intención con que el autor engarza esos personajes y episodios" (Martín Baños, 2007: 20). 
Otro tanto sucede con todo lo perteneciente a la recepción del texto. Así, como señala Martín Baños (2007: 10-11), "se imprimiera donde se imprimiera por primera vez, el manuscrito del autor debía de tener el aspecto de una larga carta [...] que jugaba a ser, recurriendo a la anonimia, la carta verdadera que un tal 'Lázaro de Tormes' dirigía a un tal 'Vuestra Merced'”. No obstante, es de suponer que más pronto que tarde se desechase la consideración de la novela como la autobiografía auténtica de un pregonero toledano (Martín Baños, 2007: 18), a pesar de que, como señala Rico (1987: 30*), desde los Discorsi intorno al comporre de i romanzi (1554), de G. Giraldi Cintio, los teóricos, al discurrir sobre la comedia nue$v a$, considerasen lícito atribuir peripecias ficticias a personajes sin relieve público. Sin embargo, la vacilación del lector ante un texto que no podía producir sino perplejidad sin duda debió perdurar, si aceptamos que la obra pretendía ofrecerse más como una falsificación que como una ficción: "los lectores acometían el libro como pura verdad y acababan encontrando una mentira que instauraba un género de ficción admirablemente nuevo" (Rico, 1987: 32*). Esa verdad, siguiendo con Rico (1987: 79*), arrancaría del acto de lenguaje como tal, esto es, del "hecho de que el pregonero escriba una carta a un determinado corresponsal [...] el contenido 'realista' de tal discurso tiene solo una importancia relativa, de segundo grado".

¿Cómo reaccionaría, pues, el lector, ante un texto para el que no estaba preparado? Difícil de decir. De cualquiera de las maneras, claro está que "la obra juega a confundir verdad y ficción. No es casual que la autobiografía de Lázaro se presente como anónima, como tampoco lo es que el molde narrativo elegido sea el epistolar" (Martín Baños, 2007: 20). De esta confluencia genérica habría de surgir, sin duda, la perplejidad. Por un lado, un lector de la época tendería a tomar al pie de la letra la obra, entendiéndola como escrita efectivamente por un Lázaro de Tormes de carne y hueso, en la medida en que la historia autobiográfica de un pregonero no podía ser recibida como ficción, ya que "un libro del corte del Lazarillo, hacia 1552, no se dejaba leer como 'ficción' de buenas a primeras: en el marco del relato en prosa, la 
categoría de 'ficción' [...] no se había aún conjugado con la realidad humilde y familiar" (Rico, 1987: 47*). Pero, por otro lado, los lectores avispados enseguida sospecharían:

La admirable ensambladura jocosa de los materiales les haría pensar en una construcción artística mejor que en el fiel trasunto de una vida. Desde ese momento, proseguirían la lectura con cien ojos, decididos a inquirir si en alguna parte se traicionaba la presunción de realidad de acuerdo con la cual habían acometido la obra; y acabarían comprobando que en rigor, interpretando el texto al pie de la letra, nunca se traicionaba: todo fluía como si fuera verdad, por más que uno estuviera convencido de que no lo era. Al final de ese camino, habían descubierto un género de ficción inédito entonces y destinado a ser centro de gravedad de la literatura europea por más de tres siglos (Rico, 1987: 77*).

En resumidas cuentas, el concepto de realismo precisa de una muy cuidadosa reformulación a uno y otro lado del Lazarillo. Por una parte, respecto a la obra seminal de 1554, no es oro todo lo que reluce. Así, la realidad impostada que la obra ofrece surge tanto de los elementos del folklore incorporados al relato como de las no escasas inverosimilitudes que la narración muestra, amén de la sorprendente estructura narrativa, de difícil calibración por parte de un lector del siglo XVI. De igual modo, La Segunda Parte de Lazarillo de Tormes retoma elementos, caracteres e incluso citas de la obra de referencia, pero por encima de todo construye una historia en apariencia disparatada - la metamorfosis del protagonista en atún -, gestando una obra en las antípodas del realismo del texto original. ¿Seguro? No olvidemos que, probablemente, ambos textos hubieron de producir idéntica perplejidad. En efecto, si con la obra de 1554 el lector se enfrentaba a un parece pero no sin precedentes en la literatura española, en la continuación antuerpiense el autor rompía cualquier expectativa de quien se acercara a la obra con las coordenadas de la obra publicada anteriormente. ¿Dónde quedan, pues, la fantasía y la realidad en 
dos obras tan distintas? Probablemente mucho más difuminadas de lo que se pudiera pensar en un principio, en la medida en que el Lazarillo no es realista, y mucho menos real, desde el momento en el que nos ofrece un prólogo donde se regalan a un pregonero de deshonroso origen y nula formación los dones de la creación literaria. Desde esta perspectiva, nada invita a descartar que el autor de la segunda parte - quien pudo optar igualmente, no lo olvidemos, por la crítica y el retrato social, si bien a partir de la construcción alegórica - pretendiera rescatar el espíritu iconoclasta de la obra original ${ }^{15}$ rompiendo con la aureola de realismo y verosimilitud sobre la que parecía auparse el Lazarillo de Tormes, convirtiendo a su (anti)héroe nada menos que en un atún.

\subsection{La crítica social: el problema de la ideología}

La cuestión de la crítica social en el Lazarillo resulta sobradamente conocida a estas alturas. En efecto, las nada inocentes referencias a distintos colectivos dotados de cierto protagonismo social, por uno u otro motivo, en el siglo XVI - clérigos, nobles, etc. - , hunde sus raíces, entre otras fuentes, en El asno de oro (Rico, 1987: 55*), del cual la obra pareció tomar también la estructura general, basada en una sarta de historietas organizadas a través del hilo conductor de la presencia del protagonista, quien ejerce a su vez también de narrador (Mascarell, 2011: 273). Pero no acaban aquí los vínculos con la obra clásica. Junto con el autobiografismo de un desafortunado, el recurso narrativo de poner a este al servicio de varios amos, a cual más déspota (Vega Rodríguez, 1987: 93), la crítica de la hipocresía o la "pintura de la vida vulgar"16 (Piñero,

15 No en vano, Rodríguez López-Vázquez (2014: 85), defensor de la idea de que el Lazarillo y su continuación han podido salir de la misma pluma, insiste en que "los trabajos críticos sobre el Lazarillo han venido descartando una hipótesis muy sencilla y perfectamente coherente: que el creador del personaje puede darle continuidad en un nuevo relato de transformaciones sin alterar en lo más mínimo sus presupuestos iniciales".

16 A este respecto, dirá Ragala (1999: 284) que "el realismo con que pretende hacer su crítica es una especie de disfraz transparente de una posible postura ideológica". 
1988: 38-39) ofrecen un claro vínculo entre nuestro texto - paradigmáticamente realista, no lo olvidemos - y una obra en la cual su protagonista sufre un fantástico proceso de metamorfosis en asno.

En efecto, la obra de Apuleyo ofrece al lector un discurso donde la crítica social aparece combinada con una descripción de tono realista tanto de ambientes como de caracteres, al tiempo que juega con el discurso fantástico mediante la herramienta de la metamorfosis del protagonista en burro. A estas alturas, obvio es que, si la obrita anónima de 1554 bebió del texto clásico, aún con más claridad lo hizo su continuación antuerpiense, tal y como señalan, entre otras, Mascarell (2011: 277). En efecto, da la impresión de que El asno de oro hubiera ofrecido dos soluciones realismo y metamorfosis del protagonista - de las que hubieran echado mano los dos textos del XVI de diferente manera, a la hora de representar la renuencia del protagonista a aceptar su estado social. Así, en el caso del texto de 1554, esto se llevaría a cabo mediante el relato de un fingido, o impostado, ascenso en el escalafón social de Lázaro, mientras que en la continuación de 1555 la estrategia pasaría por hacer uso de la herramienta de la metáfora, dando así un valor alegórico al episodio de la metamorfosis del protagonista en atún ${ }^{17}$. Sea como fuere, el episodio de la transformación de Lázaro en pez, al margen de su valor simbólico per se, sirve para llevar a cabo una clara sátira política y militar ${ }^{18}$ : "la

17 No obstante, como señala Ricapito (2013), también en el caso de la obra de 1554 el aspecto puramente externo pudiera tener un valor simbólico, en el sentido de que la hipocresía de Lázaro y su falso ascenso social - no olvidemos que uno de los temas principales de la obra "es la discrepancia entre el ser y el parecer" (Ricapito, 2013: 10) - van en conexión con su ropa: cuando sirve al capellán, gana lo bastante para comprarse ropas, aunque estas sean de ocasión, y lo mismo sucede siendo ya pregonero, cuando el arcipreste le proporcione "las calzas viejas que deja" (p. 78): "aun cuando Lazarillo trata de hacerse pasar como un hombre de bien, el hecho de que esa ropa es vieja subvierte su tentativa de ser un hombre de bien" (Ricapito, 2013: 4-5).

18 Véase Piñero (1988: 27) a propósito de la lectura de la obra en cuanto crítica a la corrupción de la Corte y al ejército español. De igual modo, Zwez (1970: 48) y 
crítica se efectúa desde la perspectiva de un hombre atunizado en una sociedad atunesca, pero se trata de una sociedad marina tan semejante en corrupción e hipocresía a la humana que no puede ser más que su reflejo bajo el océano" (Mascarell, 2011: 272). Así, La Segunda Parte de Lazarillo de Tormes continuaría la estela humanística del Renacimiento de las llamadas novelas de transformaciones (Vega Rodríguez, 1987: 91) ${ }^{19}$, retomando de El asno de oro el relato en primera persona, la metamorfosis, el encuentro del protagonista con la Verdad ${ }^{20}$ - Isis, en el caso de la obra de Apuleyo - o la transformación en humano - en el caso de la obra antuerpiense, en los capítulos XVI y XVII, cuando Lázaro es capturado por las redes de unos pescadores - (Gil, 1992: 305-306). En este sentido, no hemos de olvidar que la metamorfosis de Lázaro sobrepasa con mucho lo meramente anecdótico: tal y como indica Vega Rodríguez (1987: 92), la parte atunesca de la obra ocupa tres cuartas partes del relato y anuda todo el desarrollo anterior o posterior, contraponiendo dos sociedades, la marítima y la terrestre, con la intención satírica de contrastar las estructuras sociales.

De igual modo, y tal y como destacan, entre otros, Núñez Rivera (2017), la crítica social de los Lazarillos habría bebido también de las obras lucianescas, a partir de un débito ya constatado en los siglos XVI-XVII (Núñez Rivera, 2017: 175). En efecto, junto con el recurso de los seres metamorfoseados - en el caso del autor clásico, a propósito del gallo del Sueño, por ejemplo-, Luciano de Samósata habría proporcionado a los textos picarescos no solo una actitud abiertamente crítica hacia distintos as-

Navarro Durán (2010: 4 y 8-9) insistirán en la interpretación alegórica de la obra desde el prisma de la crítica y la burla a Carlos V: “Este rey tenía algunos defectos que recuerdan a Carlos $\mathrm{V}$ y nos sugiere la posibilidad de que el rey de los atunes sea una alegoría del Emperador" (Zwez, 1970: 48).

19 En este sentido, la propia Vega Rodríguez (1987: 91-92) insistirá en señalar que la traducción de El asno de oro fue obra de un erasmista, Diego López de Cortegana.

20 Núñez Rivera (2017: 184), por otro lado, vinculará el encuentro de Lázaro con la Verdad con los encuentros extraordinarios del náufrago con diferentes seres a lo largo de los Relatos lucianescos. 
pectos de la vida de su tiempo - desde la mención de los inconvenientes de la vida en palacio en De los que viven a sueldo hasta la denuncia de la falsa adivinación en el Pseudomantis (Alejandro o El falso profeta), pasando por el recurrente asunto de la crítica a los conocimientos y doctrinas de los filósofos-, sino una visión desenfadada de los contragéneros basados en hechos más o menos extraordinarios - no de otro modo podemos entender la naturaleza inédita, en términos literarios, de los acontecimientos narrados en el primer Lazarillo-, elementos y deudas estas que claramente habría visto el continuador de 1555 en el Lazarillo original (Núñez Rivera, 2017: 176-186):

Las pesquisas vitales y la observación satírica y crítica del comportamiento humano y de la sociedad en su conjunto, sobre todo de las falsas creencias religiosas, tal como acontece a varios de los amos, y del superficial concepto de honra basado en presupuestos distintos a la virtud, acercan en efecto la figura de Lázaro, que comenta socarronamente desde su actualidad los sucesos acontecidos, al Menipo de Luciano (Núñez Rivera, 2017: 178).

En resumen, la crítica social que vierten tanto el Lazarillo como su continuación antuerpiense, así como sus débitos para con $E l$ asno de oro o los textos de Luciano ${ }^{21}$, llevan de nuevo a replantearse la aparente distancia que aleja a ambas obras picarescas entre sí. En efecto, si, estructural o semánticamente, no son pocos los rasgos que comparten las dos obras sobre Lázaro respecto al relato de Apuleyo o los textos del autor sirio, el hecho de que El asno de oro y la producción lucianesca combinen realismo con fantasía lleva a preguntarse si en realidad los dos Lazarillos no dejan de ser respuestas complementarias para el mismo problema, desde el momento en el que la metamorfosis, entendida de diferentes formas - en cuanto impostada transformación indumentaria y social, en el caso de la obra original, y como alegórico relato, a

21 Véase también Rodríguez López-Vázquez (2018a: 831) a propósito del vínculo entre la continuación del Lazarillo y la Historia verdadera de Luciano. 
propósito de la obra de 1555-, ayuda a construir dos historias que buscan, en última instancia, llevar a cabo una acerba labor de crítica social a través de la estrategia de la insinuación.

\subsection{La estructura. Otra vuelta de tuerca a los viejos enigmas}

\subsubsection{El anonimato}

Sin lugar a dudas, el primer elemento que vincula de forma evidente los dos textos lo encontramos ya en la portada, cuando la estrategia de la supresión del nombre del autor contribuye, especialmente en el caso del relato fundacional, a crear una estrategia narrativa absolutamente rompedora: “el autor se borró voluntariamente de su obra porque se proponía alcanzar un objetivo: presentar una obra con enormes visos de veracidad" (Ragala, 1999: 274). Cierto es que, en el caso de la continuación del Lazarillo, la naturaleza fantástica de las aventuras atunescas bloquea cualquier tipo de asunción acerca de la naturaleza documental del texto, pero de igual modo la estrategia del anonimato, al margen de proteger al autor de posibles represalias - más que comprensibles al tratarse de obras donde clero o nobleza no salen especialmente bien parados $-{ }^{22}$, permite jugar a lo que Martínez Bonati (2005: 208) denomina "discurso ontológicamente ambiguo", real-ficticio, al hablar el autor real y luego, sin solución de continuidad, su doble ficticio. Es decir, el anonimato, combinado con el uso de la primera persona, propicia el desarrollo del discurso autobiográfico, más o menos impostado.

22 A este respecto, conviene recordar la atribución del texto, por parte de $\mathrm{Na}-$ varro Durán (2010: 8-10), a Diego Hurtado de Mendoza, quien habría elaborado la obra como burla del emperador Carlos V, tras ser destituido por este de todos sus cargos en 1552: "una persona que se atreve a contar al príncipe Felipe lo muy agraviado que se siente por cómo le ha tratado su padre [...] encaja perfectamente con el perfil [...] si a ello le añadimos que era prosista satírico y hombre que había leído a Luciano y a Plinio [...] las piezas unidas forman el retrato del autor de La segunda parte" (Navarro Durán, 2010: 9). Frente a la teoría de Navarro Durán, Rodríguez López-Vázquez (2018d: 34) señalará que la atribución se hace "sin aportar ninguna prueba documental ni sostener esas decisiones editoriales en principios críticos verificables". Véase también Rodríguez López-Vázquez (2018e). 


\subsubsection{Autobiografismo}

En ambas obras, como es igualmente sabido, el autor opta por el uso de la primera persona para dar forma narrativa a la historia de unas peripecias que ofrecen una aparente identidad nominal entre autor, narrador y protagonista. En efecto, la auto-reflexividad ${ }^{23}$ parece, en las obras fundacionales del género picaresco, un atributo que contribuye a crear un nuevo paradigma de novela (Friedman, 2006), a pesar de las reticencias de críticos como Martínez Bonati (2005: 205) a considerar la posibilidad ontológica de que un sujeto real se apropie del discurso novelístico. De cualquiera de las maneras, el propio Martínez Bonati (2005: 207) acabará por reconocer que, al fin y al cabo, el hablante es "el que responde por lo dicho, el que ha hecho suyas esas palabras" $\mathrm{y}$, en ese sentido, Lázaro aparece como el único responsable del acto ilocutivo tanto en la obra primigenia como en su continuación antuerpiense. Sin embargo, el uso de la ironía, del juego, a lo largo de ambos textos, contribuye a crear una suerte de dobleces enunciativas que socavan, en palabras de Friedman (2016: 28), la credibilidad del Lázaro narrador, convertido tanto en sujeto como en objeto de la narración. Y así, el efecto de ventrilocuismo que genera la ironía de un autor que, obligadamente, no puede tomarse en serio ni la historia de un donnadie analfabeto reconvertido en cultivado escribano ${ }^{24} \mathrm{ni}$ la del joven metamorfoseado de forma sorpresiva en atún, lleva a construir una obra - dos, en este caso- de enunciados ecoicos, donde el autor real se cuela

23 "The discourse - and, as would follow, discourse analysis - may be the nucleus of the story. This facet of the narrative, essentially a rhetoric and a poetics, is a primary innovation of Lazarillo de Tormes and of what would develop into the picaresque genre" (Friedman, 2016: 30).

24 A este respecto, Navarro Durán baraja la posibilidad de conceder verosimilitud a la obra mediante un acto escriturario vicario, justificado en parte en base a su teoría de que en la obra original alguien habría arrancado un folio del texto (Navarro Durán, 2003: 13-16), que permitiría esclarecer la estructura de la novela, en la cual Lázaro contaría, pero no escribiría: "Lázaro no escribe, habla (un escribano anotaría su declaración), porque no sabe escribir: nunca ha ido a la escuela ni menciona tampoco haber recibido educación alguna" (Navarro Durán, 2006: 180). 
en el texto a través de la piel de un pretendido alter ego: "the nominal writer is complemented by an extratextual Other, who inhabits the narrative in a speculative, and spectral, manner" (Friedman, 2016: 28).

De cualquiera de las maneras, cierto es que la obra original adopta un tono abiertamente confesional desde las primeras líneas - “Pues sepa vuestra merced, ante todas cosas, que a mí llaman Lázaro de Tormes" (p. 6)-, mucho más diluido en el caso de la continuación, donde tan solo se retoma el testigo del final de la edición de Alcalá - "En este tiempo estaba en mi prosperidad y en la cumbre de toda buena fortuna" (p. 80)-, el cual recuerda, en cierto modo, a las autobiografías confesionales o espirituales de la época y a los procesos del tribunal de la Inquisición, si bien desarticulando su intencionalidad primigenia, al convertir el relato en novela (Gómez-Moriana, 2007: 51 y 62; García Rubio, 2011: 228). No obstante, y al margen del componente deconstructivista que pudiera plantear el tono confesional del Lazarillo respecto al uso más o menos institucionalizado de la primera persona en el discurso público y literario del siglo XVI, lo cierto es que el recurso del autobiografismo, en ambos textos, supone reforzar una identidad enunciativa que emana ya desde la autoría empírica, gracias al anonimato, y que llega hasta el protagonista, pasando por el autor implícito y por el narrador. En el caso de La Segunda Parte de Lazarillo de Tormes, este autobiografismo solo puede concebirse como mera impostura y guiño respecto a la obra original, desde el momento en el que se sumerge al protagonista en el universo de lo simple y llanamente fantástico. No obstante, la deuda enunciativa ahí persiste, y con ella la clara intencionalidad de vincular la fórmula discursiva de los dos textos picarescos.

\subsubsection{El "caso"}

Como es sabido, la crítica contemporánea del Lazarillo ha cifrado buena parte de las claves estructurales de la novela en torno al "caso" mencionado en el prólogo - "Y pues Vuestra Merced escribe se le escriba y relate el caso muy por extenso, 
parescióme no tomalle por el medio, sino del principio, porque se tenga entera noticia de mi persona" (p. 5) - y en el último de los tratados: "Hasta el día de hoy nunca nadie nos oyó sobre el caso" (p. 79). En efecto, el relato se articularía a partir de esa carta-respuesta que Lázaro remitiría al narratario - "Vuestra Merced" - , ante la petición de información requerida por el "caso" mencionado en el prólogo. Ahora bien, una de las cuestiones sobre la que sigue sin haber consenso es: ¿el caso del prólogo y el del tratado VII son el mismo? Mientras un número significativo de críticos, desde Claudio Guillén (1957) en adelante, lo afirma sin paliativos ${ }^{25}$, otros, valorando el sentido "muy genérico y muy incoloro del sustantivo caso", consideran que no hay razones de peso para conectar "intrépidamente el segundo caso (que se refiere a los chismes) sobre el del prólogo (que se refiere a la satisfacción 'existencial' de Lázaro, ganada a pulso)" (Alatorre, 2002: 436), sugiriendo así, más bien, que el "caso" de Lázaro en sí es la narración de la vida misma del pregonero (García Rubio, 2011: 229; Carrasco, 1987), tal y como defienden, entre otros, García de la Concha (1981), para quien el caso de amancebamiento de una mujer casada con un clérigo era "irrelevante y tópico" (García Rubio, 2011: 230). Por otro lado, desde esta lectura, carecería de sentido que Lázaro quisiese delatar a su mujer, sea o no inocente, puesto que, de hacerlo, le originaría no solo la pérdida de toda su fortuna, sino el fin de su acomodada vida (García Rubio, 2011: 236), lo que lleva a pensar que muy poco interés tendría el protagonista en hacer de este episodio el elemento nuclear del relato ${ }^{26}$.

25 Véanse, como ejemplos, Rico (1970), Lázaro Carreter (1983: 42) o Navarro Durán (2006: 181 y 2016: 18), por citar algunos casos.

26 Según la Pragmática de 25 de noviembre de 1552, Lázaro habría sufrido como castigo la pena de vergüenza pública, cinco años de galeras y la pérdida total de su patrimonio (García Rubio, 2011: 245), lo que justifica sobradamente que "hasta el día de hoy nunca nadie nos oyó sobre el caso" (p. 79). De igual modo, como apunta Ruffinatto (2011: 176), la justicia solo podía actuar después de recibir una denuncia explícita del marido, que es lo último que quiere Lázaro, por eso juega a decir sin confirmar en el tratado VII. 
Como muy certeramente apunta Alatorre (2002: 445), la lectura ingenua del tratado VII del Lazarillo es tan legítima como la malintencionada, lo que supone que tan válido puede ser creer en la buena fe del protagonista como ver en toda su declaración un excelente ejercicio de cinismo literario. A efectos prácticos, el tratado VII no hace sino poner sobre la mesa, una vez más, la dualidad interpretativa de que disfruta el Lazarillo, paradigmáticamente ejemplificada con la cuestión del "caso", el cual puede tener de por sí un carácter anafórico, presuponiendo un contenido consabido por los interlocutores (Carrasco, 2001: 50), plantear con una vaguedad semántica absoluta algún tipo de referencia a cuestiones o asuntos de toda índole, o bien, como parecen apuntar quienes ven un vínculo entre el prólogo de la obra y el tratado VII, aludir a algún tipo de acontecimiento de naturaleza más o menos críptica.

Si echamos un vistazo al Lazarillo, podemos constatar que no son tan solo dos las ocasiones en que el narrador opta por el uso de la palabra "caso". En efecto, junto con la referencia a la desaparición del escudero - "Yo les dije que aún no era venido. Venida la noche y él no, yo hube miedo de quedar en casa solo, y fuime a las vecinas y contéles el caso, y allí dormí" (p. 65)-, encontramos otros usos más residuales del vocablo: "en caso de medicina decía que Galeno no supo la mitad que él para muela" (p. 14); "y porque vea Vuestra Merced a cuánto se estendía el ingenio deste astuto ciego, contaré un caso de muchos que con él me acaescieron" (p. 19); "puesto caso que yo no había menester muchas salsas para comer, todavía me holgaba con las cortezas del queso que de la ratonera sacaba" (pp. 38-39). De cualquiera de las maneras, y al margen de que, en efecto, encontremos la palabra en más ocasiones de las que se suele indicar - si bien, en honor a la verdad, con muy poco peso narrativo, a diferencia de las menciones del prólogo y del último de los tratados-, llama poderosamente la atención el hecho de que no se haya utilizado como referencia La Segunda Parte de Lazarillo de Tormes a la hora de ponderar el verdadero peso estructural del "caso" en la obra 
primigenia. En efecto, como sabemos, la continuación antuerpiense fue publicada un año más tarde que las ediciones de que disponemos del Lazarillo primigenio, con lo que es de suponer que el autor de la secuela se hiciera eco de la recepción contemporánea de la obra, máxime teniendo en cuenta que, tal y como estamos repasando, la continuación del Lazarillo contiene no pocas alusiones y guiños a una obra que, como resulta obvio, constituye su referencia fundamental. De este modo, es más que probable que las páginas de La Segunda Parte de Lazarillo de Tormes se hayan hecho eco del posible impacto - de haberlo tenido- que el uso del vocablo "caso" tuvo en la lectura coetánea del Lazarillo.

Ante todo, la palabra figura en la continuación en un número de ocasiones considerablemente superior al del texto original. Unas quince veces encontramos la palabra, si bien en muchas de ellas - diez, más o menos-, su presencia apenas merece ser comentada, careciendo de peso específico dentro de la narración. Así, entre los casos más reseñables, poco invita a pensar en referencias de naturaleza críptica que guardasen relación con el ménage à trois del tratado VII del Lazarillo, sirviendo en ocasiones como sinónimo de "acontecimiento" - "en tanta manera me vi favorecido, que me parece si entonces matara un hombre, o me acaeciera algún caso recio, hallara a todo el mundo de mi bando" (p. 126) - , y otras veces para destacar su naturaleza fórica, en relación con alguna mención alusiva a acontecimientos incluidos unas líneas atrás: “yo le rogué mucho se aclarasse cómo, y no quiso [...] se fue no alegre, dexándome a mí muy triste y confuso. Pensé muchos y varios pensamientos sobre aquel caso" ( $p$. 170); "passé yo por la memoria muchas cosas en este caso" (p. 171); "ellos respondieron todos que estaban prestos a seguirme y hacer en el caso su deber" (p. 186); "sois perdonado vos y todos lo de vuestra compañía [...] que en el caso pasado os dieron favor y ayuda" (p. 210). De igual modo, a veces, la palabra "caso" tan solo sirve como fórmula con la que retomar el hilo narrativo principal - "pues, tornando a lo que hace al caso" (p. 161)-, pero la mayoría de las veces su presencia es irrelevante desde el 
punto de vista narrativo, o simplemente repite los usos destacados anteriormente: "el cual era caso feo" (p. 152); "qué poco caso hacen de las vidas ajenas" (p. 157); "puesto caso que en la tierra alguno se allegasse a comer algo de lo de su próximo" (p. 160); "y fue el caso que, viéndole yo tan aficionado a las armas, le dixe que él debía enviar" (p. 167); "de quien el rey y todo el mar más caso haría" (p. 168); "y fue el caso que [...] él quisiera que me fuera luego del exército" (p. 173); "aquel había sido un caso feo" (p. 214) o "no hicieran más caso de mí aquellos diablos" (p. 257).

En conclusión, es posible que una atenta relectura de La Segunda Parte de Lazarillo de Tormes permita comprobar en qué medida características que hoy en día atribuimos al Lazarillo original sean fruto más del entusiasmo por incorporar quilates a esa joya de orfebrería que es el texto de 1554 que verdadera consecuencia de una detenida labor de análisis, a partir de los datos de que disponemos. En este sentido, y a pesar de los más que repetidos guiños al Lazarillo que encontramos en su continuación antuerpiense, ni uno solo de los usos de la palabra "caso" invita a pensar en la más ligera alusión al amancebamiento de la mujer del protagonista, lo que no deja de ser sorprendente si, en efecto, el objetivo principal del Lazarillo era elaborar una epístola con la que aclarar el incómodo episodio final del triángulo amoroso. Por tanto, si a un versado lector de mediados del XVI preocupado por jugar con los motivos y elementos fundamentales de la primera obra picaresca la referencia al "caso" del prólogo se le pasó desapercibida, difícilmente podemos arrogarnos la pericia necesaria como para encontrar la llave del tesoro en una palabra tan vacía semánticamente como "caso".

\subsection{4 "Vuestra Merced"}

Junto con el "caso", el peso del narratario constituye otro de los pilares sobre el que la crítica viene apoyándose en las últimas décadas. Una de las primeras cuestiones que suele aflorar al respecto es el valor de este a la hora de justificar la propia existencia de la narración. Así, como apuntaba Rico (1987: 65*), “si preten- 
día pasar por auténtica, por real, la autobiografía de un insignificante pregonero de Toledo no era aceptable como texto independiente [...] El autor anónimo, perfectamente al tanto de la posible objeción, la zanjó de raíz en las primeras líneas". En efecto, solo la presencia de algún tipo de autoridad, pretendiendo recabar información, permitía el relato por escrito y de forma pública de la insignificante y deshonrosa vida de un donnadie. No obstante, la irrupción del ya célebre "Vuestra Merced" - "Suplico a Vuestra Merced reciba el pobre servicio de mano de quien lo hiciera más rico [...] Y pues Vuestra Merced escribe se le escriba y relate el caso muy por extenso" (p. 5) - suponía, como se ha hecho notar en muchas ocasiones (Navarro Durán, 2006: 180), una incongruencia respecto al destinatario inespecífico inmediatamente anterior - "Yo por bien tengo que cosas tan señaladas, y por ventura nunca oídas ni vistas, vengan a noticia de muchos y no se entierren en la sepultura del olvido" (p. 3) -, lo cual, al margen de que se haya perdido o no alguna página justificativa del salto narrativo, supone una evidencia aún más clara del interés por incluir la figura de "Vuestra Merced" como narratario directo de la historia, y por tanto como pilar fundamental a la hora de justificar la narración.

Ahora bien, una cosa es asumir a "Vuestra Merced" como destinatario, y otra considerar el relato desde un plano puramente escrito. En este sentido, ya Guillén (1957), Rico (1970) y Lázaro Carreter (1983) habían insistido en la idea de que el Lazarillo es en realidad una carta o epístola hablada (Gómez-Moriana, 2007: 40), en la medida en que en la obra ni siquiera se dice que "Vuestra Merced" haya escrito a Lázaro directamente - no olvidemos el célebre "Y pues Vuestra Merced escribe se le escriba" (p.5) ${ }^{27}-$,

27 De igual modo, como apunta Ruffinatto (2001: 165-166 y 175), el impersonal "escribe se le escriba" no permite saber si el destinatario del texto original era Lázaro, o al menos el responsable de la respuesta, pudiendo considerársele, simplemente, como el receptor indirecto de la petición. En este sentido, el crítico italiano considera que lo más probable es que el narratario de la obra se hubiera dirigido a alguna institución religiosa, desde donde el escándalo habría llegado a oídos de Lázaro. 
o incluso pudiera considerarse que la petición no ha llegado a ser formulada de forma escrita, sino orall ${ }^{28}$.

Pero, ¿qué sabemos en realidad de la identidad de "Vuestra Merced"? A ciencia cierta, más bien poco o nada. Ruffinatto (2001: 165) indica que lo único que sabemos con seguridad es que se trata del remitente de una carta que ha de proporcionar informes sobre un "caso", que merece un tratamiento que le ubica justo a continuación de Dios - "en el cual el día de hoy vivo y resido a servicio de Dios y de Vuestra Merced" (p. 77) -, que es amigo del arcipreste, pero ejerce un ministerio superior a este, y que con ocasión de las Cortes convocadas en Toledo por Carlos $\mathrm{V}$, no se encontraba en la ciudad: "fue el mismo año que nuestro victorioso Emperador en esta insigne ciudad de Toledo entró y tuvo en ella Cortes, y se hicieron grandes regocijos, como Vuestra Merced habrá oído" (p. 80). A partir de ahí, toda clase de elucubraciones se despliegan, en función de la línea argumentativa que desarrolle el crítico en cuestión. Y así, al margen de hipótesis más o menos aventuradas, como la de que "Vuestra Merced" pudiera ser nada más y nada menos que Carlos V ${ }^{29}$ (Brenes, 1992), las tesis fundamentales van en la línea de considerar que pudiera tratarse de un superior eclesiástico, preocupado por el ménage à trois del arcipreste (Ruffinatto, 2001: 174), o quizás de un amigo del clérigo - a lo mejor un inquisidor, un visitador, otro canónigo de la catedral de Toledo, el deán o incluso el arzobispo-, quien habría pedido que se hiciera una relación del "caso", para

28 Así, como apunta Gómez-Moriana (2007: 41), la referencia a la escritura ni siquiera implica necesariamente la existencia de una carta: en el español de la época puede significar tan solo una orden, la de dar cuenta de su vida, en el caso de Lázaro de Tormes. En este mismo sentido, García Rubio (2011: 243) considera que el fragmento "hablando con reverencia de Vuestra Merced, porque está ella delante" (p. 79), del tratado VII, invita a pensar en una suerte de declaración oral, al modo inquisitorial.

29 Lo cual parece oponerse de forma más o menos antagónica a la postura de quienes, como Navarro Durán (2010: 8-10) o Rodríguez López-Vázquez (2014: 107), sostienen que el texto muestra una crítica - cuando no burla - a la política y a la figura del emperador Carlos V. 
informarse de episodios denunciables o de irregularidades del pueblo (Vaquero Serrano, 2001; Archer, 1985). De igual modo, en los últimos años la tesis de Navarro Durán (2003: 16-22, 2006: 182183 y 2016: 11, 12, 16 y 18) acerca de la consideración de "Vuestra Merced" como una mujer ${ }^{30}$ ofrece una nueva perspectiva sobre un asunto que parece estar lejos de verse agotado.

$\mathrm{Al}$ igual que con el "caso", llama poderosamente la atención, en relación con el narratario del Lazarillo, la ausencia de cotejo respecto a su presencia en la continuación antuerpiense. De igual modo, es aún más llamativo que no se haya barajado para "Vuestra Merced" la misma hipótesis que para el "caso": ¿podríamos encontrarnos ante diferentes personas, según el pasaje, respecto a las cuales Lázaro utiliza idéntica fórmula de tratamiento? Veámoslo con más calma. En primer lugar, en la obra original la expresión "Vuestra Merced" figura casi en una veintena de ocasiones, al menos si tenemos en cuenta las interpolaciones de la edición de Alcalá. Así, desde las menciones del prólogo, sin duda las que más claramente remiten al narratario - "Suplico a Vuestra Merced reciba el pobre servicio de mano de quien lo hiciera más rico, si su poder y deseo se conformaran. Y pues Vuestra Merced escribe se le escriba y relate el caso muy por extenso, pareciome no tomalle por el medio, sino del principio" (p. 5)-, junto con la del comienzo de la narración - “Pues sepa Vuestra Merced, ante todas cosas, que a mí llaman Lázaro de Tormes" (p. 6) -, la obra irá alternando alusiones que de forma obvia si-

30 En efecto, Navarro Durán (2003: 16-22, 2006: 182-183 y 2016: 11, 12, 16 y 18), a partir del uso del pronombre femenino en el tratado VII y de las disculpas en relación con la mención del verbo parir - "me han certificado que antes que conmigo casase había parido tres veces, hablando con reverencia de Vuestra Merced, porque está ella delante" (p. 79)-, considera que el narratario ha de ser una mujer, excluyendo sin embargo a la pareja del protagonista. Así, habría de referirse al femenino más cercano, que es "Vuestra Merced", no teniendo sentido que le pida excusas al arcipreste por usar el verbo parir y que además añada la tautología de que lo hace porque está él delante. "Vuestra Merced" no estaría, pues, delante de Lázaro, pero a él/ella irían destinadas sus palabras - es decir, estaría delante cuando las lea-, siendo en conclusión una mujer que presumiblemente tuviera al arcipreste de confesor, y respecto al cual tuviera dudas acerca de su discreción o catadura moral. 
guen remitiendo al destinatario de la narración - “Huelgo de contar a Vuestra Merced estas niñerías" (p. 13); "Vuestra Merced sepa que [...] en su oficio era un águila" (p. 13); "Quiero que sepa Vuestra Merced" (p. 14); "Y porque vea Vuestra Merced" (p. 19); "como adelante Vuestra Merced oirá" (p. 24); “Vuestra Merced crea" (p. 47), etc. - con otras en las cuales la fórmula de tratamiento se destina a alguno de los personajes de la historia, como el escudero - "no eran dadas las ocho cuando con Vuestra Merced encontré" (p. 47); "ninguna pena tenga Vuestra Merced" (p. 50); "vi que Vuestra Merced no venía" (p. 54)-, o a algún personaje referido en diálogos entre los protagonistas: "Mantenga Dios a Vuestra Merced" (p. 62); "Beso las manos de Vuestra Merced" (p. 63). Y llegamos por fin al tratado VII, donde "Vuestra Merced" aparecerá, al menos en la edición de Alcalá, en cinco ocasiones: "En el cual el día de hoy vivo y resido a servicio de Dios y de Vuestra Merced" (p. 77); "el señor arcipreste de Sant Salvador, mi señor, y servidor y amigo de Vuestra Merced" (p. 77); "hablando con reverencia de Vuestra Merced, porque está ella delante" (p. 79); "se hicieron grandes regocijos, como Vuestra Merced habrá oído" (p. 80) y "De lo que de aquí adelante me suscediere, avisaré a Vuestra Merced" (p. 296). ¿Qué podemos concluir de todo ello? En primer lugar, que la figura del narratario cobra especial protagonismo en el prólogo y en el tratado VII. En segundo lugar, que, si bien hay casos en los cuales el uso de "Vuestra Merced" claramente remite al destinatario del relato, o al de las conversaciones habidas entre los personajes, a veces su uso goza de cierta ambigüedad, en particular en el celebérrimo y problemático "hablando con reverencia de Vuestra Merced, porque está ella delante" (p. 79). En efecto, si seguimos la cuidada edición de Rico (Anónimo, 2011), poco invita a pensar en un salto enunciativo/diegético entre la conversación que está teniendo lugar entre Lázaro y el arcipreste y el nivel narrador-narratario. ¿Podemos concluir por ello que "Vuestra Merced", al menos en este caso, se refiere al arcipreste? Quizás, a pesar de las dudas, entre otros, del propio Rico (1987: 133). ¿Nos 
lleva ello a la conclusión de que el arcipreste es el destinatario de la obra? En modo alguno, si recordamos que apenas unas páginas antes Lázaro ha disociado bien a ambos destinatarios de sus palabras: "teniendo noticia de mi persona el señor arcipreste de Sant Salvador, mi señor, y servidor y amigo de Vuestra Merced" (p. 77). ¿Qué podemos extraer de todo ello? Muy poco, salvo que hay un destinatario de la obra denominado "Vuestra Merced", que tiene algún tipo de relación con el arcipreste, y que quizás hemos corrido demasiado rápido a la hora de pensar que pudiera tratarse de una mujer, amparados en el "hablando con reverencia de Vuestra Merced, porque está ella delante" (p. 79). Este ella pudiera remitir al arcipreste - dudoso-, a la mujer de Lázaro - poco probable-, a un tercero - que pudiera o no coincidir con el "Vuestra Merced" narratario de otras alusiones de la obra - , presente en uno u otro nivel diegético - ya que lo mismo las palabras pudieran proceder del Lázaro personaje como del Lázaro narrador - , o simplemente ser fruto de alguna omisión o errata, llevando el anacoluto o el despiste tipográfico a toda clase de labores heurísticas estériles. De cualquiera de las maneras, quizás sea prudente considerar que, al igual que sucediera con el "caso", la fórmula de tratamiento "Vuestra Merced" era una moneda de uso demasiado corriente como para pensar en un valor exclusivamente unívoco en el texto.

En cuanto a La Segunda Parte de Lazarillo de Tormes, encontramos la expresión "Vuestra Merced" catorce veces, siendo usada igualmente tanto para dirigirse a otros personajes de la historia, en este caso tan solo el arcipreste - "señor [...] no se altere vuestra merced" (p. 241); "vuestra merced ni nadie de mis amigos" (p. 245); "Mas vuestra merced me la haga de sentarse" (p. 245) - como al narratario: "Sepa Vuestra Merced" (p. 130); "que habrían contado a Vuestra Merced" (pp. 132-133); "pues sé que de todo lo que en ella pasó y vio Vuestra Merced estará, como he dicho informado" (P. 133); "según Vuestra Merced oirá" (p. 134); "porque sepa Vuestra Merced" (p. 219); "si a Vuestra Merced hubiesse de escrebir" (p. 231); "cuando sea Vuestra Merced servido, 
si quisiere, le enviaré la relación” (p. 231); “Viera vuestra merced a Lázaro" (p. 252); "Viera Vuestra Merced a Lázaro entonces" (p. 254); "Viera Vuestra Merced mi gargajear" (p. 255); "Prometo a Vuestra Merced que hubo de callar el bueno del rector" (p.256) o "Lo demás, con el tiempo, lo sabrá Vuestra Merced" (p. 259).

De entre las muestras localizadas en La Segunda Parte de Lazarillo de Tormes podemos extraer conclusiones de cierto interés, sobre todo si seguimos manteniendo la tesis de que su autor fue un lector muy atento de la obra original: 1) la fórmula de tratamiento se usa tanto con el narratario como con alguno de los personajes; 2) no hay ninguna mención directa, cuando se dirige al narratario, que aclare su identidad; 3 ) hay referencias directas al acto enunciativo de Lázaro en cuanto desarrollado tan solo en el plano oral (p. 134), y alguna alusión más o menos ambigua a la posibilidad de que el discurso pudiera transcurrir en el nivel del lenguaje escrito (p. 231); 4) en los únicos casos en los que se ha de optar por un género $u$ otro a la hora de dirigirse al narratario, se opta por el masculino "informado" y "servido" (pp. 133 y 231, respectivamente), y 5) el uso de "Vuestra Merced", fuera de la relación narrador-narratario, se usa tan solo para tratar a un único personaje: el arcipreste. Obviamente, si de estas conclusiones alguna pudiera tener cierto valor, estas han de ser sin duda la cuarta y la quinta. Es decir, si seguimos asumiendo que el autor de la continuación antuerpiense tomó buena nota de la estructura y elementos del texto original, en calidad de lector coetáneo de la obra primigenia, todo invita a pensar que, para los lectores del siglo XVI, el destinatario de la carta-epístola de Lázaro era un hombre, lo que desmontaría la tesis de Navarro Durán (2003: 1622, 2006: 182-183 y 2016: 11, 12, 16 y 18). Más difícil es de asumir la segunda conclusión, esto es, que, fruto de su uso en la obra antuerpiense, lleguemos a la asunción de que el autor de la continuación considerase que había un intencionado propósito de vincular el uso de "Vuestra Merced" en la obra original, más allá de casos particulares residuales, con un único individuo, tanto en el plano de la enunciación como en el del enunciado. De ser 
ciertos los pensamientos del autor de la secuela de Amberes, y de haber acertado en su hipótesis, todo nos llevaría a la conclusión de que "Vuestra Merced" es el arcipreste de San Salvador, lo cual es a todas luces imposible teniendo en cuenta el dualismo que se plantea en el tratado VII de la obra de 1554 - "el señor arcipreste de Sant Salvador, mi señor, y servidor y amigo de Vuestra Merced" (p. 77) -, pero deja asentada la duda de si para buena parte de los lectores del XVI esta pudo ser la impresión que se llevasen tras la lectura del Lazarillo.

\subsubsection{El arcipreste}

El arcipreste de San Salvador constituye sin duda uno de los personajes más interesantes de la obra, fruto más de lo que insinúan él o el protagonista que de lo que verdaderamente sabemos de forma explícita gracias a la narración. Ya Vaquero Serrano (2001) y Archer (1985) habían barajado la posibilidad de que el sacerdote, y no "Vuestra Merced", fuese el auténtico destinatario de la carta de Lázaro, lo cual reforzaría la tesis, apuntada en el apartado anterior, de que, a juzgar por la construcción de la continuación antuerpiense, todo invita a pensar en una más que evidente confusión/identificación entre el arcipreste y el narratario de la novela. De cualquiera de las maneras, el propio Vaquero Serrano (2001) señaló igualmente cómo ni en la iglesia de San Salvador de Toledo ni en el propio Toledo existía la categoría eclesiástica de arcipreste, lo cual llevaría a la conclusión de que la caracterización del personaje fuese fruto de la fantasía o del deseo de evitar problemas con el clero.

En la obra de 1554, como es sabido, la figura del arcipreste solo aparece al final del texto, en el tratado VII. En concreto, Lázaro remite a dicho personaje, y a su categoría eclesiástica, de forma expresa tan solo en dos ocasiones: "teniendo noticia de mi persona el señor arcipreste de Sant Salvador [...] procuró casarme con una criada suya" (p. 77) y "Y, así, me casé con ella, y hasta agora no estoy arrepentido, porque, allende de ser buena hija y diligente servicial, tengo en mi señor arcipreste todo favor y ayu- 
da" (p. 78). En otras dos Lázaro remitirá a él usando el respetuoso "mi señor": "allende de no ser ella mujer que se pague destas burlas, mi señor me ha prometido lo que pienso cumplirá" (p. 78) y "mas yo de un cabo y mi señor de otro tanto le dijimos y otorgamos, que cesó su llanto" (p. 79).

Respecto a La Segunda Parte de Lazarillo de Tormes, al margen de la presencia, de nuevo, del personaje, y de las fórmulas religiosas - "Y bien me lo desviaba mi señor el Arcipreste" (p. 131); "agora sale el arcipreste de San Salvador de la casa del corregidor" (p. 242) - y de respeto - "torné a llamar y dar golpes a la puerta, y mi señor, enojado, se levantó y púsose a la ventana" (p. 241); "truxo conmigo a mi señor" (p. 244); "supliqué al carcelero tornasse a casa de mi señor y le rogasse de su parte" (p. 246); "de mi señor y de mi mujer fui conocido" (p. 247) - con las que el pícaro y otros personajes se refieren a él, sin duda llama la atención el afán del Lázaro narrador por incidir en las lúbricas relaciones del sacerdote con la mujer del protagonista, las cuales parecen ofrecer a todas luces una clara situación de reciprocidad correspondida: "Díxelo a mi mujer y ella, con gana de volverse con mi señor el Arcipreste, me dixo" (p. 131); “al fin, como a mí se me habían assentado los negros celos, aun como atún, que por ventura había pasado por ellos con la mi Elvira y mi amo el arcipreste" (p. 172); "fui a la de mi señor el arcipreste, y estaban ya durmiendo, y tantos golpes di que los desperté [...] la mi Elvira muy ásperamente me respondió" (p. 241). De igual modo, resulta especialmente interesante el hecho de que, como apunta Piñero (1988: 244), "por primera vez en la historia de Lázaro conocemos el nombre del arcipreste": " $\mathrm{OH}$, mi señor Rodrigo de Yepes $^{31}$, arcipreste de San Salvador, mirad cuál está el vuestro buen criado Lázaro de Tormes atormentado y cargado de hierros!" (p. 244).

31 Poco valor tendrá esto, no obstante, desde el punto de vista documental, a partir del momento en el que aceptamos que se trata de un "nombre a todas luces ficticio, al igual que el cargo, inexistente en la iglesia de San Salvador" (Rodríguez López-Vázquez, 2014: 166). 
En conclusión, La Segunda Parte de Lazarillo de Tormes otorga un mayor protagonismo al arcipreste dentro de la obra, quizás como consecuencia de la lectura atenta que del tratado VII de la novela original pudo hacer el autor, lo que probablemente le hizo concluir que la figura religiosa, dentro del triángulo amoroso, había de volverse más evidente y menos sutil. Para ello, Lázaro hablará ya sin tapujos del amancebamiento de su mujer con el clérigo, al tiempo que, joh, sorpresa!, nos desvela su nombre y apellido, dándole así una fisicidad que le despoja de su envoltura eclesiástica y lo deja reducido a su básica condición de hombre.

\subsubsection{La mujer}

Tal y como apunta Alegre (1984), uno de los rasgos reseñables que supone la presencia de personajes femeninos en el Lazarillo es el hecho de que, respecto a la literatura anterior, y salvo contadas excepciones, todas las mujeres, incluida la madre del protagonista, aparecen descritas con rasgos morales negativos/ reprochables. En el caso del texto de 1554, la mujer de Lázaro, como el arcipreste, no aparecerá hasta el último de los tratados $\mathrm{y}$, al igual que este, sin nombre propio: "ven a mi mujer irle a hacer la cama y guisalle de comer" (p. 78); "no ser ella mujer que se pague destas burlas" (p. 78); "viendo entrar en mi casa a tu mujer" (p.78); "entonces mi mujer echó juramentos sobre sí" (p. 79); "si me quieren meter mal con mi mujer" (p. 80) y "es tan buena mujer como vive dentro de las puertas de Toledo" ( $\mathrm{p}$. 80). Esta carencia de identidad de la mujer del protagonista se ve reforzada por el hecho de que nunca llega a asumir el uso de la palabra de forma directa: "echó juramentos sobre sí" (p. 79) o "tomose a llorar y a echar maldiciones sobre quien conmigo la había casado" (p. 79).

Respecto a la continuación antuerpiense, de nuevo encontramos a la mujer del pícaro, a quien se refiere el protagonista con frecuencia de forma indirecta - "que tenía en mi casa de comer yo y mi mujer hasta hartar una semana entera" (p. 127); "muy contento y pagado con mi mujer" (p. 130); "mi persona muy bien 
tratada [...] y mi mujer lo mismo" (p. 131); "mi mujer no me desconocerá" (p. 243); "la palabra que me había dado de traer consigo a mi mujer" (p. 246); "de mi señor y de mi mujer fui conocido" (p. 247) -, si bien acaba por otorgarle la palabra: "Díxelo a mi mujer, y ella, con gana de volverse con mi señor el Arcipreste, me dixo: - Haced lo que quisiéredes" (p. 131). No obstante, al objeto de dar mayor peso al personaje, como había sucedido con el arcipreste, el autor de la segunda parte convierte a la mujer de Lázaro en madre - "porque no fuera menos de haber mi mujer e hija" (p. 230); “de ver a mi mujer y a mi niña" (p. 240)-, con serias dudas en torno a la paternidad de la criatura: "mi mujer parió [...] aunque yo tenía alguna sospecha, ella me juró que era mía" (p. 129). Por otro lado, y al igual que había sucedido con el arcipreste, la mujer del pícaro logrará al fin un antropónimo: "por ventura había pasado por ellos con la mi Elvira y mi amo el arcipreste" (p. 172); "al que me los diera a la mi Elvira en Toledo, para con que casar a la niña con alguno" (p. 229); "la mi Elvira muy ásperamente me respondió a grandes voces" (p. 241) y "lo que haré por vos será traer aquí a Elvira, mi ama" (p. 245).

En resumen, el tratamiento que recibe la figura de la mujer de Lázaro dista poco del recibido por el arcipreste, en la continuación de la obra. Así, a aquella, como a este, le dará mayor protagonismo y entidad, otorgándole el don de la palabra, convirtiéndola en madre - con serias dudas, eso sí, sobre la identidad del padre- y bautizándola al fin, tal y como sucediera con el religioso. Por ello, La Segunda Parte de Lazarillo de Tormes invita a pensar en un especial interés por parte del autor por realzar los otros dos vértices del triángulo amoroso, volviendo explícito lo implícito - el amancebamiento, se entiende - y dotando de vida a dos personajes que, en la obra original, estaban totalmente subordinados a la figura de Lázaro.

\section{Conclusión}

La Segunda Parte de Lazarillo de Tormes ha venido arrastrando desde poco después de su publicación - y dejando de lado cierto 
éxito inicial - el lastre de haber nacido a la sombra de una de las obras más importantes de la literatura española. Como consecuencia de ello, y de su bizarro contenido, en comparación con la obra de referencia, ha tenido que bregar con toda clase de juicios descalificadores, coronados con las lapidarias afirmaciones Menéndez Pelayo.

Obvio es que la obra muestra no pocas deudas para con el texto original: personajes, trama y estructura enunciativa nos recuerdan una y otra vez que el texto no deja de ser, por encima de todo, una continuación. En este sentido, la inclusión del episodio nuclear de la metamorfosis de Lázaro en atún supone, en apariencia, un salto cualitativo infranqueable entre un texto que se arroga la quintaesencia de la novela realista y una obra ante la cual el lector tiene que aceptar impertérrito que el protagonista se convierta en pez. Sin embargo, esa sensación de inestabilidad ontológica que, durante su metamorfosis, transmite Lázaro (Hasson, 2014: 101), nos lleva a replantearnos la noción difusa de realismo y verosimilitud. En efecto, ni con el Lazarillo es oro todo lo que reluce - el lector ha de hacer no pocas concesiones en aras del disfrute, tanto en el plano del discurso como en el de la historia-, ni su continuación nos lleva a un escenario nuevo, pues al fin y al cabo la segunda parte no hace sino resquebrajar el horizonte de expectativas del receptor de la misma manera que un año antes lo hiciera la obra original, al irrumpir en medio de un panorama literario sobrecargado de caballeros, sufridores pastores y perseverantes parejas de enamorados.

Respecto a la crítica social - tan clara y debatida en el caso del Lazarillo-, la continuación antuerpiense opta por no dejarla de lado, si bien recurre al mecanismo de la alegoría para convertir a los atunes en un trasunto de los políticos y militares españoles del XVI. De igual modo, la secuela de 1555 retoma elementos estructurales clave, como el anonimato o el autobiografismo. En este sentido, el tratamiento que la palabra "caso" recibe en la obra de Amberes, carente de entidad semántica, invita a pensar que, para el lector del XVI, quizás el triángulo amoroso de la 
obra original en modo alguno figurase en el prólogo a modo de justificación del relato, viéndose tan solo como un mero ejemplo de coincidencia léxica. De igual modo, de los usos de "Vuestra Merced" en la segunda parte podemos colegir que, de nuevo según el autor de la continuación, el narratario del texto original pudiera ser un hombre y quizás, a pesar de los problemas estructurales que esto plantearía, el propio arcipreste. Por último, tanto este como la mujer de Lázaro cobran en la continuación una inusitada presencia, otorgándoseles incluso un nombre propio, al tiempo que la voz relatora convierte al fin en explícito lo que era todo un secreto a voces: el amancebamiento de la mujer del protagonista con el arcipreste.

En resumen, y al margen de su incuestionable interés literario - que lo tiene, y mucho-, La Segunda Parte de Lazarillo de Tormes ha sido desatendida, a pesar de ser un magnífico documento con el que intentar aproximarnos, con un testimonio de primera mano, a la recepción que el texto primigenio pudo tener en el momento de su publicación y a la comprensión de cómo sus coetáneos leyeron, interpretaron y entendieron algunos de los elementos hoy en día más controvertidos de la obra original. Ojalá poco a poco vayan cayendo los prejuicios, y la continuación antuerpiense del Lazarillo comience a ser vista también como el primer estudio crítico de nuestra gran novela picaresca.

\section{Referencias Bibliográficas}

Alatorre, A. (2002) "Contra los denigradores de Lázaro de Tormes", Nueva Revista de Filología Hispánica, L/2, 427-455.

Alegre, J. M. (1984) "Las mujeres en el Lazarillo de Tormes", Arbor: Ciencia, Pensamiento y Cultura, 460, 23-35.

Anónimo (2014) Segunda parte del Lazarillo de Tormes, ed. A. Rodríguez López-Vázquez, Madrid, Cátedra.

Anónimo (2011) Lazarillo de Tormes, ed. F. Rico, Barcelona, Real Academia Española/Círculo de Lectores.

Anónimo (1987) Lazarillo de Tormes, ed. F. Rico, Madrid, Cátedra. 
Anónimo (1988) Segunda Parte del Lazarillo, ed. P. M. Piñero, Madrid, Cátedra.

Archer, R. (1985) “The fictional context of Lazarillo de Tormes", The Modern Language Review, LXXX, 478-484.

Brenes, D. (1992) “¿Quién es V. M. en el Lazarillo de Tormes?", Boletín de la Biblioteca de Menéndez Pelayo, LXVIII, 73-89.

Campra, R. (2008) Territorios de la ficción. Lo fantástico, Sevilla, Renacimiento.

Carrasco, F. (1987) “La cara olvidada de 'el caso' de Lázaro de Tormes", Thesaurus. Boletín del Instituto Caro y Cuervo, XLII, 1-7.

Cavillac, M. (2010) “Una fuente probable del Guzmán: la segunda parte antuerpiense del Lazarillo (1555)", en "Guzmán de Alfarache" y la novela moderna, Madrid, Casa de Velázquez, 61-71.

Friedman, E. H. (2016) "Guzmán de Alfarache and the Question of Form", eHumanista, 34, 27-43.

Friedman, E. H. (2006) Cervantes in the Middle: Realism and Reality in the Spanish Novel from Lazarillo de Tormes to Niebla, Newark, Juan de la Cuesta Hispanic Monographs.

García de la Concha, V. (1981) Nueva lectura del "Lazarillo". El deleite de la perspectiva, Madrid, Castalia.

García Rubio, F. (2011) “El 'wikileak' del caso Lázaro de Tormes: Problemáticas jurídicas y jurisdiccionales", eHumanista, 18, 228-247.

GARgano, A. (2006) "La novela picaresca entre realismo y representación de la realidad: el caso del Buscón", La Perinola, 10, 123-131.

GiL, J. (1992) "Apuleyo en la Sevilla renacentista", Habis, 23, 297-306.

Gómez-Moriana, A. (2007) “De 'Vuestra Merced' al ‘vulgo' y al '[curioso] lector' u 'oidor'. Sobre la función de la segunda persona en el relato picaresco", Sociocriticism, XXII/1-2, 39-64.

González Salvador, A. (1984) “De lo fantástico y de la literatura fantástica", Anuario de Estudios Filológicos, VII, 207-226.

Guillén, C. (1957) “La disposición temporal del Lazarillo de Tormes", Hispanic Review, 25, 264-279. 
Hasson, O. (2014) “Hacia una lectura de la conversión en la Segunda Parte del Lazarillo (Amberes, 1555)", Humanística/Conversos, 2, 94-106.

Herrero Cecilia, J. (2016) “Sobre los aspectos fundamentales de la estética del género fantástico y su evolución desde lo fantástico 'romántico' a lo fantástico 'posmoderno'", Cédille. Revista de estudios franceses, 6, 15-51.

Juliana BazÁn, N. (2014) "Apuntes preliminares en torno a la relación literatura fantástica y contexto", (Pensamiento), (palabra) y obra, 11, 52-62.

Lázaro Carreter, F. (1983) "Lazarillo de Tormes" en la picaresca, Barcelona, Ariel.

Lomeña Cantos, A. (2013) “El espacio y lo fantástico en la novela desde la teoría de mundos posibles: una revisión de las tipologías semánticas de la ficción", Brumal. Revista de Investigación sobre lo Fantástico, I/2, 373-389.

Martín Baños, P. (2007) "Nuevos asedios críticos al Lazarillo de Tormes, I", Per Abbat, 3, 7-22.

Martínez Bonati, F. (2005) "Modos inverosímiles de narrar y los guiños narratológicos de Cervantes", Estudios Públicos, 100, 193-208.

Martínez Mata, E. (1984) “Notas sobre realismo y verosimilitud literaria en el Lazarillo de Tormes", Archivum, 34-35, 105-117.

Mascarell, P. (2011) “Lazarillos y metamorfosis. Estudio de las relaciones entre El asno de oro, el Lazarillo de Tormes y su Segunda parte", Lemir, 15, 271-284.

Menéndez Pelayo, M. (1978) Historia de los heterodoxos españoles, II, Madrid, BAC.

Navarro Durán, R. (2003) “Introducción”, en Valdés, A. de, La vida de Lazarillo de Tormes, y de sus fortunas y adversidades, Barcelona, Octaedro, 7-102.

Navarro Durán, R. (2006) “Un nuevo ámbito para La vida de Lazarillo de Tormes", Estudis Romànics, XXVIII, 179-197. 
Navarro Durán, R. (2010) “Diego Hurtado de Mendoza, autor de la Segunda Parte de Lazarillo de Tormes", Clarín. Revista de Nueva Literatura, 85, 3-10.

Navarro Durán, R. (2016) “Dar la palabra al texto de La vida de Lazarillo de Tormes", Revista canadiense de estudios hispánicos, XLI/1, 11-33.

NúÑez Rivera, V. (2017) "Atisbos lucianescos en los Lazarillos", en Darnis, P., Canonica, E., Ruiz Pérez, P. y Vian Herrero, A. (eds.), Sátira menipea y renovación narrativa en España: del lucianismo a Don Quijote, Bordeaux/Córdoba, Presses Universitaires de Bordeaux/Editorial Universitaria de Córdoba, 2017, 175-194.

NúÑez Rivera, V. (2003) “Claves para el segundo Lazarillo, 1555. El continuador anónimo interpreta su modelo", Bulletin Hispanique, 2, 333-369.

Piñero, P M. (2014) “La Segunda parte del Lazarillo (1555). Suma de estímulos diversos o los comienzos 'desconcertados' de un género nuevo", Criticón, 120-121, 171-199.

Piñero, P. M. (1988) “Introducción”, en Anónimo, Segunda Parte del Lazarillo, Madrid, Cátedra, 7-122.

Podadera Solórzano, E. (2014) “Fortuna y adversidades de una digna continuación: a propósito de la nueva edición de la Segunda parte del Lazarillo de Tormes (Alfredo Rodríguez LópezVázquez, Cátedra, 2014)", Revista Internacional Digilec, 1, 176-183.

Ragala, S. (1999) “Tradición literaria y realismo en Lazarillo de Tormes", Estudios humanísticos. Filología, 21, 271-284.

Reis Pereira, D. N. (2013) "Considerações sobre o fantástiCo", Memento, 4/2, 1-21.

Ricapito, J. V. (2013) "La figura del escudero del Lazarillo de Tormes, sus gestos y vestimenta", Studia Philologica Valentina, 15, 3-12.

Rico, F. (1987) “Introducción”, en Anónimo, Lazarillo de Tormes, Madrid, Cátedra, 13*-136*.

Rico, F. (1970) La novela picaresca y el punto de vista, Barcelona, Seix Barral. 
Rodríguez Hernández, T. (2009-2010) “La conspiración fantástica: una aproximación lingüístico-cognitiva a la evolución del género", Espéculo, 43, disponible en https://webs.ucm.es/info/ especulo/numero43/consfan.html [fecha de consulta, 18/07/2018].

Rodríguez López-VÁzquez, A. (2014) "Introducción", en Anónimo, Segunda parte del Lazarillo de Tormes, Madrid, Cátedra, 11-186.

Rodríguez López-Vázquez, A. (2016) “Las dos partes del Lazarillo de Tormes, la Reforma Protestante y la atribución a Francisco de Enzinas", Janus, 5, 49-64.

RodríGuez López-VÁzquez, A. (2017) “La Historia verdadera de Luciano, la traducción de Enzinas y el Lazarillo. Hacia una autoría compartida", Etiópicas, 13, 55-63.

Rodríguez López-VÁzquez, A. (2018a) “Dos microsistemas predictivos en el Lazarillo de Tormes: evidencias para la atribución a Francisco de Enzinas", eHumanista, 38, 820-833.

RodríGuez López-VÁzquez, A. (2018b) "Índices excluyentes e índices inclusivos en la atribución del Lazarillo", Artifara, 18, 1-5.

Rodríguez López-VÁzquez, A. (2018c) "Las dos partes del Lazarillo y su autor. Un estudio de estilometría", Janus, 7, 55-91.

Rodríguez López-VÁzquez, A. (2018d) “Los índices excluyentes en las atribuciones del Lazarillo", Lemir, 22, 33-52.

Rodríguez López-VÁzquez, A. (2018e) “Sobre la atribución de la segunda parte del Lazarillo a Hurtado de Mendoza: algunos errores metodológicos", Artifara, 18, 143-151.

Rosa, J. y SuÁrez, J. L. (2016) “The Life of Lazarillo de Tormes and of His Machine Learning Adversities. Non-traditional authorship attribution techniques in the context of the Lazarillo", Lemir, 20, 373-438.

Ruffinatto, A. (2011) “Revisión del 'caso' de Lázaro de Tormes (puntos de vista y trompes-l'oeil en el Lazarillo)", Edad de Oro, XX, 163-179.

Todorov, T. (1982) Introducción a la literatura fantástica, Barcelona, Ediciones Buenos Aires. 
Torres Rabassa, G. (2015) “'Otra manera de mirar”. Género fantástico y literatura del absurdo: hacia una impugnación del orden de lo real", Brumal. Revista de Investigación sobre lo Fantástico, III/1, 185-205.

VAldés, A. de (2003) La vida de Lazarillo de Tormes, y de sus fortunas y adversidades, ed. R. Navarro Durán, Barcelona, Octaedro.

Vaquero Serrano, M. del C. (2001) “Una posible clave para el Lazarillo de Tormes: Bernardino de Alcaraz, ¿el arcipreste de San Salvador?", Lemir, 5, disponible en http://parnaseo.uv.es/ Lemir/Revista/Revista5/Arcipreste/Vaquero.htm [fecha de consulta, 25/07/2018].

Vega Rodríguez, P. M. (1987) “Notas sobre la personificación de los peces en el Lazarillo de 1555", Estudios humanísticos. Filología, 9, 91-100.

Videira Álvarez, J. (2015) “Esquizoanálisis del deseo y literatura fantástica", Brumal. Revista de Investigación sobre lo Fantástico, II/2, 155-175.

Zwez, R. E. (1970) Hacia una revalorización de la Segunda Parte del Lazarillo (1555), Valencia, Albatros. 
